\title{
Critical molecular pathways in CLL therapy
}

\author{
Gerardo Ferrer $^{1}$ and Emili Montserrat ${ }^{2 *}$
}

\begin{abstract}
Chronic lymphocytic leukemia (CLL), the most frequent type of leukemia in western countries, is characterized by the progressive accumulation in blood, bone marrow and lymphoid tissues of monoclonal B lymphocytes with a characteristic immunophenotype. Despite advances in therapy and improved outcome, in most instances CLL is an incurable disorder. Signaling via the B-cell receptor (BCR), the upregulation of anti-apoptotic proteins, and the cross-talk between CLL cells and microenvironment constitute key factors in the pathogenesis of CLL. Currently, inhibitors of kinases like BTK or PI3K blocking BCR signaling, and molecules that mimic the BH3 domain to compete with $\mathrm{BCL}-2$ are established tools in the treatment of CLL. As the complex biology of CLL is rapidly unfolding, the number of small molecules targeting CLL molecular pathways is increasing and it is likely that they will further improve the outcome of patients with this form of leukemia.
\end{abstract}

Keywords: CLL, BTK, PI3K, BCl-2 and pathway inhibitors

\section{Background}

Chronic lymphocytic leukemia (CLL) is the most frequent type of leukemia in western countries, with an incidence of 5.82/100000 inhabitants in the USA (Li et al., 2015). The median age at diagnosis is 72 years, with a higher incidence in males (1.7:1) (Li et al., 2015; Hallek, 2017; Kipps et al., 2017). CLL is characterized by the clonal expansion of $\mathrm{B}$ cells with a characteristic immunophenotype (i.e., smIg ${ }^{\text {weak }}, \mathrm{CD} 29^{+}, \mathrm{CD} 23^{+}, \mathrm{CD} 20^{\text {weak }}$ ) that slowly accumulate in peripheral blood, bone marrow, and lymphoid tissues mainly as a result of defects in the apoptosis machinery such as the overexpression of Bcl2 family antiapoptotic proteins (Hallek, 2017; Kipps et al., 2017; Billard, 2014). The clinical course of patients with CLL is heterogeneous with some patients succumbing a few months after diagnosis and others having prolonged survival and dying for reasons other than leukemia. The clinical heterogeneity of CLL does reflect differences in the biology of the disease, particularly the IGHV mutational status and chromosomal alterations (i.e., del13q, del11q, trisomy 12 and del17p). Beside del17p/TP53 mutation which is the strongest CLL biomarker for response to therapy, other mutations (e.g., SF3B1, ATM, NOTCH1, BRIC3) have been reported to

\footnotetext{
* Correspondence: emontse@clinic.ub.es

${ }^{2}$ Department of Hematology, Institute of Hematology and Oncology,

University of Barcelona, Hospital Clínic, Villarroel 170, 08036 Barcelona, Spain Full list of author information is available at the end of the article
}

correlate with the outcome of the disease, but they are not actionable yet (Lazarian et al., 2017).

In spite of major advances in its therapy, CLL remains largely incurable. However, in the past two decades important progress has been made in the understanding of the biology of CLL at different levels (e.g., B-cell receptor (BCR) signaling, anti- and pro-apoptotic proteins, and the microenvironment) (Kipps et al., 2017). This progress has resulted in the advent of small molecules and kinase inhibitors as new and effective therapies for CLL. In this paper, we review the main CLL molecular pathways that promote the survival and growth of CLL B cells and outline treatment results with agents targeting such pathways.

\section{$B$ cell receptor and signaling}

The BCR is a key for the fate of B cells and plays an important role in the survival of CLL cells. The BCR is connected to a network of kinases and phosphatases that tune and amplify its activation (Stevenson et al., 2011; Seda \& Mraz, 2015). Each normal mature B cell has a unique antigen-binding site as a result of random rearrangement of IGH and IGL gene segments. The probability that two independent $\mathrm{B}$ cell clones present the same BCR is extremely small $\left(10^{-9}-10^{-12}\right)$. However, approximately $30 \%$ of patients with CLL express similar, if not identical, BCRs with common ("stereotyped") features (Stamatopoulos et al., 2017). 
This suggests that these cells are selected based on the structure of the antigen-binding domains of the smIg, presumably due to the recognition of similar antigens which could be associated with CLL pathogenesis. Patients within a BCR-stereotyped subset have a similar clinical behavior. Another important observation in the relationship between $\mathrm{BCR}$ and the mutational status of the immunoglobulin heavy chain variable region gene $(I G H V)$. Patients with fewer than $2 \%$ of mutations present a more polyreactive $\mathrm{BCR}$, poor biomarkers, more aggressive disease and shorter survival (Hamblin et al., 1999; Damle et al., 1999).

Continuous BCR signaling translates into the phosphorylation of intermediate members and secondary pathways such as AKT, ERK and NF-kB (Stevenson et al., 2011). Opposite to what is observed in diffuse large B cell lymphoma, this "tonic" signaling is not due to mutations in BCR signaling components (Davis et al., 2010; Philippen et al., 2010) but to the recognition of various autoantigens and other microbial or environmental components, including DNA, cytoskeletal nonmuscle myosin heavy chain IIA, apoptotic cells, and LPS (Burger \& Chiorazzi, 2013). In addition, CLL BCRs are able to bind each other and induce signaling; this is a peculiar feature only additionally observed in some murine polyreactive B1 cell BCRs (Duhren-von Minden et al., 2012). More recently, the crystal structures of a set of CLL BCRs led to the identification of the regions involved in the binding. Interestingly, the strength of the interaction seems to control the pace of the disease (Minici et al., 2017).

Finally, BCR binding initiates signaling by the phosphorylation of Ig $\alpha$ and $\operatorname{Ig} \beta$ by Lyn and other Src family kinases. Then SYK, BTK, and PI3Ks turn active, modulating several pathways affecting survival, proliferation and migration of CLL cells (Fig. 1).

\section{Targets and agents blocking B-cell receptor signaling Bruton's tyrosine kinase, BTK}

The gene encoding BTK is located on the $\mathrm{X}$ chromosome and was initially discovered in X-linked agammaglobulinemia (Vetrie et al., 1993). BTK is expressed in cells of all hematopoietic lineages except $\mathrm{T}$ - and plasma cells (Smith et al., 1994). It transmits, diversifies, and amplifies signals from a wide variety of surface molecules. BTK inhibitors block BCR signaling, thus strongly influencing cell survival, proliferation and migration (Burger \& Buggy, 2013). In addition, BTK is critical to B cell motility and tissue homing, regulating the response to $\mathrm{CXCL} 12$ and integrins released by microenvironment

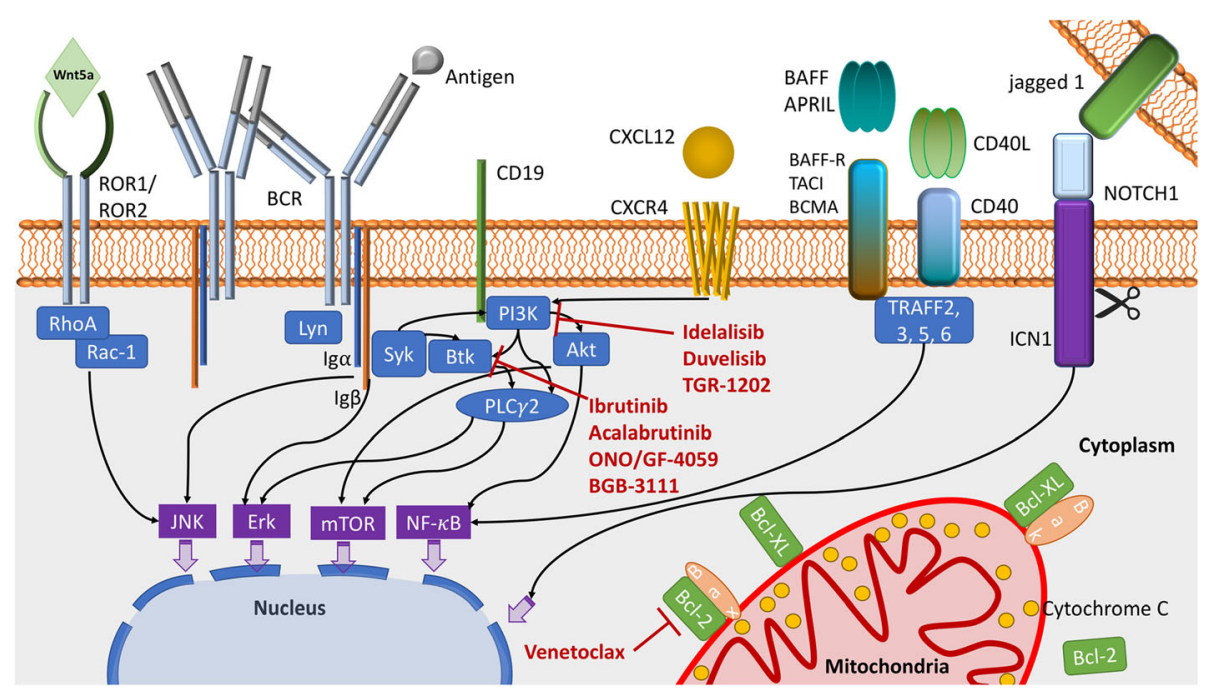

Fig. $1 \mathrm{CLL}$ main pathogenic pathways and target agents against BTK, PI3K and BCl-2. BCR signaling is induced by the recognition of an antigen or by self-binding, Lyn promotes the phosphorylation of Iga and lgb that activates the spleen tyrosine kinase (Syk). Syk then triggers the formation of a multi-component 'signalosome', including Btk, Akt, PI3K and PLCY2 among others. BCR co-receptor CD19 is important for PI3K activation, which recruits and activates PLCY2, BTK and AKT. These leads to the activation of the c-Jun N-terminal kinase (JNK), MEK-extracellular signal-regulated kinase (ERK), mechanistic target of rapamycin (mTOR) and (NF-KB) signaling pathways. In addition, CLL cells activate these and other prosurvial, activatory pathways by their interaction with many soluble and surface factors. As an example: Wnt5a interact with the ROR1/ROR2 dimers promoting the activation of RhoA and Rac-1. CXCR4/CXCL12 engagement activates PI3K and downstream pathways, in addition other molecules. The TNF receptors CD40, BAFF-R, TACl and BCMA interact with their ligands CD40L or BAFF and APRIL, inducing the activation of the canonical and alternative NF-KB pathways depending on the TNF receptor-associated factor (TRAF). NOTCH1 signaling is initiated by the binding with one of the five ligands (e.g. jagged 1, Delta-like ligand 1 (DLL1)), followed by the release of the intracellular active portion (ICN1), enabling its migration into the nucleus. These pathways lead to the upregulation of anti-apoptotic molecules like Bcl-2, BCl-XL and Mcl-1, sequestering the pro-apoptotic molecules Bax and Bak, and inhibiting the intrinsic apoptosis pathway. Inhibitors for PI3K, BTK and BCl-2 are indicated in red 
cells (de Gorter et al., 2007), which explain the traffic of lymphocytes between lymph nodes and blood, and the lymphocytosis observed in subjects treated with BTK inhibitors (Chen et al., 2016; Woyach et al., 2014).

\section{Ibrutinib}

Ibrutinib is the first orally bioavailable small-molecule to inhibit BTK. It forms a covalent bond with Cys481 in the active site of BTK, preventing its phosphorylation (Honigberg et al., 2010). Despite a short circulating halflife, the covalent binding allows almost the complete occupancy of BTK active sites in peripheral blood mononuclear cells for $24 \mathrm{~h}$ (Advani et al., 2013). The first results of ibrutinib as single agent in the treatment of CLL were remarkable. The overall response rate (ORR) in previously treated patients with high-risk disease was $71 \%$, and the 2-year progression free survival (PFS) was $75 \%$ (Byrd et al., 2013). These results were validated in consecutive trials. Of note, ibrutinib improved the outcome of patients with del17p and relapsed/refractory $(\mathrm{R} / \mathrm{R})$ disease with a median progression free survival approximating 30 months (Table 1) (Burger et al., 2014; Byrd et al., 2014; O'Brien et al., 2016). In a study with long follow-up (PCYC-1102/1103, NCT01105247/ NCT01109069), 5- year PFS rates were 43\% in 101 patients with R/R CLL and $92 \%$ in 31 treatment naïve (O'Brien et al., 2016). However, there is no plateau in the remission duration curves, and almost one third of patients discontinued treatment due to toxicity, CLL progression or Richter's transformation (Woyach, 2017).

CLL relapse on ibrutinib is mainly due to the acquisition of mutations in BTK or PLCG2, its direct downstream target (Woyach, 2017; Maddocks et al., 2015; Woyach et al., 2014). These mutations are found in 85$90 \%$ of patients at relapse by next generation sequencing (Ahn et al., 2017) and can be present a long time before clinical relapse is observed (Burger et al., 2016). The most common mutation in BTK is C481S, this mutation reduces the affinity of the ibrutinib-BTK binding, inducing a reversible inhibition (Woyach et al., 2014; Cheng et al., 2015). Conversely, PLCG2 mutations are associated with a gain-of-function, allowing signaling even when BTK is blocked (Woyach et al., 2014; Zhou et al., 2012).

The most important adverse events occurring with ibrutinib treatment are bleeding, hypertension, atrial fibrillation, cutaneous rash, and infections. Many of these side effects have been attributed to off-target effects of ibrutinib on epidermal derived growth factor receptor (EGFR), TEC family proteins, and ITK (interleukin-2-inducible tyrosine kinase). These side effects could be partially offset by second-generation BTK inhibitors in advanced clinical development such as ACP-196 (acalabrutinib), ONO/GS-4059, and BGB-3111, which virtually have no inhibitory effect over EGFR, TEC, and ITK (Wu et al., 2016). Inhibition of EGFR signaling has been associated with cutaneous rash and severe diarrhea (Lynch Jr. et al., 2007), while the risk of bleeding might be due to the dependency of platelets to TEC for platelet aggregation (Atkinson et al., 2003; Hamazaki et al., 1998). Finally, a set of $\mathrm{T}$ cells are dependent on TEC and ITK signaling (Andreotti et al., 2010), thus new generation BTK inhibitors might improve anti-tumoral $\mathrm{T}$ cell responses.

\section{PI3K}

Phosphoinositide-3 kinase (PI3K) was initially described in association with the polyoma middle $\mathrm{T}$ protein (Whitman et al., 1985). PI3Ks affect a diverse array of biological processes in cells, including proliferation, differentiation, survival, and metabolism. BCR activation induces the recruitment of $\mathrm{CD} 19$ along with PI3K to the membrane to propagate and amplify signaling (Fig. 1). PI3K class 1 is constituted by a catalytic and a regulatory subunit, and each subunit has different isoforms. The catalytic subunits include $\alpha, \beta, \gamma$ and $\delta$ isoforms and the regulatory subunit involves p 85 and p101/55. Importantly, the catalytic subunits $\alpha$ and $\beta$ are expressed ubiquitously, while the subunits $\gamma$ and $\delta$ are present predominantly in leukocytes. It is considered, therefore, that the inhibition of these subunits could reduce treatment toxicity (Engelman et al., 2006; Vanhaesebroeck et al., 2010; Furman et al., 2014).

\section{Idelalisib}

Idelalisib (CAL-101, GS-1101) is the first orally competitive inhibitor of the PI3K $\delta$ isoform, able to block survival and homing signals in CLL including those produced by the BCR and the chemokine receptors CXCR4 and CXCR5 (Brown et al., 2014; Lannutti et al., 2011). In a phase I study in patients with relapsed CLL, idelalisib resulted in an ORR of $72 \%$ and PFS at 16 months of 50\% (Brown et al., 2014). Subsequent phase III trials investigated idelalisib in combination with rituximab or ofatumumab resulting in a significant increase of the PFS and OS as compared to idelalisib alone (Furman et al., 2014; Jones et al., 2017). However, these responses were shorter than in patients treated with ibrutinib (Table 1). Interestingly, TP53 lesions and complex karyotype do not seem to reduce treatment effectiveness, but the number of trials is small and their follow-up short (Fruman \& Cantley, 2014; Kreuzer et al., 2016) suggesting caution in drawing robust conclusions about this otherwise important issue.

Patients treated with idelalisib present an unusual pattern of toxicity including enteritis/diarrhea $(<20 \%)$ (not infrequently appearing as "late" events), transaminitis $(<15 \%)$ and pneumonitis $(<5 \%)$. Fifteen percent of patients present a grade 3-4 toxicities and are generally responsible for idelalisib discontinuation (Lampson et al., 2016; Louie 
Table 1 Clinical trials with pathway inhibitors in CLL

\begin{tabular}{|c|c|c|c|c|c|c|c|c|c|}
\hline $\begin{array}{l}\text { Agent } \\
\text { (Study) }\end{array}$ & $\begin{array}{l}\mathrm{N} \\
(\mathrm{R} / \mathrm{R}-\mathrm{TN})\end{array}$ & $\begin{array}{l}\text { Age in years } \\
\text { (Range) }\end{array}$ & $\begin{array}{l}\text { Median } \\
\text { follow-up } \\
\text { in months } \\
\text { (Range) }\end{array}$ & $\begin{array}{l}\text { TP53/ } \\
\text { d17p }\end{array}$ & CK & $\begin{array}{l}\text { ORR } \\
(\mathrm{CR})\end{array}$ & $\begin{array}{l}\text { PFS (2y) } \\
\text { (median in months) }\end{array}$ & $\begin{array}{l}\text { OS }(2 y) \\
\text { (median in } \\
\text { months) }\end{array}$ & Ref. \\
\hline Ibrutinib & 132 & 68 & 46 & 34 & 41 & $86 \%$ & n.r. & n.r. & (O'Brien et al., 2016) \\
\hline (NCT01 105247/NCT01109069) & $(101-31)$ & $(37-84)$ & $(0-67)$ & & & $(14 \%)$ & (not reached) & (not reached) & \\
\hline \multirow[t]{2}{*}{ Ibrutinib + rituximab } & 40 & 65 & 47 & 21 & $15 / 28$ & $95 \%$ & $62 \%$ & $78 \%$ & (Jain et al., 2017) \\
\hline & $(36-4)$ & $(35-82)$ & $(36-51)$ & & & $(23 \%)$ & (45mo) & (not reached) & \\
\hline Ibrutinib & 84 & n.r. & 34 & 53 & n.r. & n.r. & $84 \%$ at $3 y$ & n.r. & (Ahn et al., 2017) \\
\hline (NCT01500733) & $(32-52)$ & & $(0.1-50)$ & & & & (not reach) & & \\
\hline Ibrutinib & 144 & 64 & 28 & 144 & n.r. & $83 \%$ & $63 \%$ & $75 \%$ & (O'Brien et al., 2016) \\
\hline (NCT01744691) & $(144-0)$ & (n.r.) & (n.r.) & & & $(n . r)$. & (not reached) & (not reached) & \\
\hline \multirow{2}{*}{$\begin{array}{l}\text { Ibrutinib }+/ \text { - rituximab }+ \text { - } \\
\text { bendamustine }\end{array}$} & 88 & 66 & 28 & $34 / 40$ & $21 / 56$ & $94 \%$ & n.a. & n.r. & (Thompson et al., 2015) \\
\hline & $(88-0)$ & $(35-83)$ & $(14-48)$ & & & $(17 \%)$ & & & \\
\hline Ibrutinib & 195 & 67 & 19 & $79 / 154$ & $39 / 153$ & $90 \%$ & $74 \%$ & $86 \%$ at $1.5 y$ & (Brown et al., 2018) \\
\hline (NCT01578707) & $(195-0)$ & $(30-86)$ & $($ n.r.-26) & & & & (n.r.) & (n.r.) & \\
\hline Ibrutinib & 621 & 60 & 17 & $26 \%$ & $73 / 216$ & n.r. & $64 \%$ & $79 \%$ & (Mato et al., 2016) \\
\hline Connect $^{\oplus}$ CLL Registry & $(536-80)$ & $(22-95)$ & (n.r.) & & & & (35mo) & (not reached) & \\
\hline Ibrutinib & 315 & 69 & 16 & $90 / 263$ & n.a. & n.r. & $74 \%$ at $1 y$ & $84 \%$ at $1 y$ & (Forum, 2016) \\
\hline UK CLL Forum & $(315-0)$ & $(42-93)$ & (n.r.) & & & & (n.r.) & (n.r.) & \\
\hline Ibrutinib & 95 & 69 & 10 & $50 / 80$ & n.a. & $84 \%$ & $75 \%$ at $1 y$ & $82 \%$ at $1 y$ & (Winqvist et al., 2016) \\
\hline Swedish CUP & $(94-1)$ & $(42-86)$ & (n.r.) & & & (3\%) & (not reached) & (not reached) & \\
\hline Idelalisib & 54 & 63 & n.r. & 13 & n.a. & $72 \%$ & n.r. & n.r. & (Brown et al., 2014) \\
\hline (NCT00710528) & $(54-0)$ & $(37-82)$ & & & & & $(16 \mathrm{mo})$ & (not reach) & \\
\hline Idelalisib + rituximab & 110 & 71 & 13 & 46 & n.a. & $81 \%$ & $38 \%$ & $72 \%$ & (Furman et al., 2014) \\
\hline (NCT01539512) & $(110-0)$ & $(48-90)$ & (n.r.) & & & $(0 \%)$ & (19mo) & (not reached) & \\
\hline Idelalisib + ofatumumab & 174 & 68 & 16 & 70 & n.a. & $75 \%$ & $\approx 30 \%$ & $\approx 65 \%$ & (Jones et al., 2017) \\
\hline (NCT01659021) & $(174-0)$ & $(61-74)$ & (n.r.) & & & $(<1 \%)$ & $(16 \mathrm{mo})$ & (not reached) & \\
\hline Idelalisib + bendamustine & 207 & 62 & 14 & 69 & n.a. & n.r. & $48 \%$ & $75 \%$ & (Zelenetz et al., 2017) \\
\hline (NCT01569295) & $(207-0)$ & $(56-69)$ & (n.r.) & & & & (21mo) & (not reached) & \\
\hline Venetoclax & 116 & 66 & 17 & 31 & n.a. & $79 \%$ & $52 \%$ & $84 \%$ & (Roberts et al., 2016) \\
\hline (NCT01328626) & $(116-0)$ & $(36-86)$ & $(1-26)$ & & & $(20 \%)$ & (25 mo) & (not reached) & \\
\hline Venetoclax + rituximab & 49 & 68 & 28 & $10 / 32$ & n.a. & $86 \%$ & $82 \%$ & $94 \%$ & (Seymour et al., 2017) \\
\hline (NCT01682616) & $(49-0)$ & $(50-88)$ & $(1-42)$ & & & $(51 \%)$ & (not reached) & (not reached) & \\
\hline Venetoclax & 107 & 67 & 12 & 107 & n.a. & $79 \%$ & $72 \%$ at $1 y$ & $87 \%$ at $1 y$ & (Stilgenbauer et al., 2016) \\
\hline (NCT01889186) & $(107-0)$ & $(37-85)$ & (n.r.) & & & $(16 \%)$ & (not reached) & (not reached) & \\
\hline
\end{tabular}

$R / R$ Relapsed/Refractory, TN Treatment Naive, CK Complex Karyotype, n.r. No reported, n.a. No applicable, mo Months, $y$ Year

et al., 2015). Importantly, in treatment-naïve patients the combination of idelalisib with anti-CD20 monoclonal antibodies may result in severe liver and gastrointestinal toxicity mediated by $\mathrm{CD}^{+} \mathrm{T}$ cells (Lampson et al., 2016; Louie et al., 2015). Due to opportunistic infections, monitoring CMV and prophylaxis for Pneumocystis jirovecii pneumonia is recommended (Cheah \& Fowler, 2016).

Two other PI3K inhibitors are in advanced clinical development. Duvelisib is a dual PI3K $\delta$ and $\gamma$ inhibitor, and TGR-1202 is a next-generation $\delta$ inhibitor with a reduced hepatic toxicity and colitis compared to other PI3K $\delta$ inhibitors (Balakrishnan et al., 2015; Mato et al., 2016).

\section{Apoptosis}

Apoptosis or programmed cell death is a critical process for the development, homeostasis and the prevention of tumorigenesis. Escaping the apoptotic program is one of the hallmarks of cancer and a key mechanism in resistance to therapy (Hanahan \& Weinberg, 2011). The apoptotic program is constituted by two main activation pathways: the extrinsic, initiated by the ligation of death receptors, and the intrinsic, where several intracellular signals control the balance between anti-apoptotic Bcl-2 family members and the pro-apoptotic Bax and Bak to initiate the mitochondrial membrane permeabilization 
(Fig. 1). These two pathways converge in activating the caspase family of proteases (Strasser et al., 2011).

The prolonged survival of CLL cells is in part associated with defective apoptosis and microenvironment mediated signals (e.g., CD40L, BAFF, APRIL, CXCL12, and VACM1 (Kipps et al., 2017; ten Hacken \& Burger, 2014) that trigger the NF-KB and PI3K/AKT pathways. These pathways are constitutively activated in CLL and promote the overexpression of Bcl-2 family members. In fact, if Bcl-2 and $\mathrm{Mcl}-1$ are suppressed, CLL cells undergo apoptosis (Hussain et al., 2007).

Approximately half of all patients with CLL have a leukemic clone with a deletion on $13 q$ which includes the loss of two microRNAs miR-15a and miR-16-1. These microRNAs diminish the expression of several proteins including the anti-apoptotic $\mathrm{Bcl}-2$ (Cimmino et al., 2005). Another common alteration in CLL cells is the mutation of TP53 or the deletion of 17p that contains this gene, an important apoptosis regulator (Zenz et al., 2009; Pospisilova et al., 2012; Bieging et al., 2014).

\section{Targets and agents regulating CLL apoptosis $B C L-2$}

The B-cell lymphoma $2(B C L-2)$ gene is located in the chromosome 18 and was initially discovered in the chromosomal translocation $\mathrm{t}(14 ; 18)(\mathrm{q} 32 ; \mathrm{q} 21)$ in follicular lymphomas (Tsujimoto et al., 1984). BCL-2 locates at the outer membrane of the mitochondria, sequestering the proapoptotic proteins Bax and Bak and preventing them from oligomerization, and inducing mitochondrial membrane permeabilization. The sequestered Bax and Bak can be released by family's BH3-only members such as Bim, Puma, Bid, Bad, and Noxa by binding to and antagonizing Bcl-2 family proteins (Strasser et al., 2011). Bcl-2 has been found to be overexpressed in CLL cells, where it mediates tumor cell survival and has been associated with resistance to therapy (Billard, 2012; Shehata et al., 2010).

\section{Venetoclax}

Venetoclax is an oral small-molecule designed to block Bcl-2 prosurvival activity by emulating the $\mathrm{BH} 3$ domain. Venetoclax is a re-engineering of navitoclax, which showed clinical efficacy but was accompanied with thrombocytopenia caused by Bcl-XL inhibition (Souers et al., 2013). Venetoclax was first evaluated in 3 refractory patients with CLL and resulted in tumor lysis syndrome in $24 \mathrm{~h}$ (Souers et al., 2013). Tumor lysis syndrome is due to rapid leukemic cell death and the release of their cellular contents into the blood stream. Consequently, a dose escalation schedule was chosen in a phase II trial on refractory del(17q) patients with CLL (Stilgenbauer et al., 2016). With a median follow-up slightly longer than 12 months, the ORR was $85 \%$ and the CR rate was $8 \%$. Of note, the ORR is not superior to that found with BTK or
PI3K inhibitors, but a proportion of patients achieve CR with undetectable MRD. In CLL, venetoclax showed to be well tolerated but some patients presented grade 3-4 adverse effects including neutropenia, infections, anemia and thrombocytopenia. These results suggest that Bcl-2 inhibition induced by venetoclax offers an opportunity to effectively treat patients with del (17p) (Table 1). Resistance to venetoclax is largely driven by microenvironment signals that promote the expression of $\mathrm{Mcl}-1$ and $\mathrm{Bcl}-\mathrm{XL}$, reducing venetoclax efficiency, especially in nodal tissues (Bose et al., 2017). Notably, therapy with BCR axis inhibitors such as ibrutinib (Cervantes-Gomez et al., 2015), acalabrutinib (Patel et al., 2017a), and duvelisib (Patel et al., 2017b) results in a decline in MCL-1 protein levels in CLL cells, providing a mechanism-based rationale to combine them with venetoclax. Such treatment combinations (e.g. venetoclax + ibrutinib) are currently under investigation (Billard, 2014; Bose et al., 2017; Seymour et al., 2017).

\section{Microenvironment}

Neoplastic CLL cells are highly dependent on interactions with the microenvironment for their survival and proliferation. Main components of the microenvironment are monocyte-derived nurselike cells (NLCs), and other myeloid cells, mesenchymal-stromal cells, T cells and NK cells, all of which communicate with CLL cells through a complex and intertwined network of adhesion molecules, chemokine receptors, tumor necrosis factor (TNF) family members, and soluble factors (reviewed in (Ten Hacken \& Burger, 2016).

The CLL microenvironment is becoming an important treatment target. Lenalidomide is an orally active immunomodulatory agent, which interferes with a wide variety of the components of the CLL microenvironment. Lenalidomide does not induce apoptosis of leukemic cells in vitro, but in vivo it upregulates receptors of B cell activation on CLL cells, together with an enhancement of the host immune response, thus inducing the recognition of CLL cells (Chanan-Khan et al., 2011; Chen et al., 2011). The mode of action is disease specific but cereblon has been identified as the main target of lenalidomide and may underlie many of its effects (Itchaki \& Brown, 2017). As a single agent, lenalidomide is effective in CLL $R / R$ and treatment-naïve patients (Chen et al., 2011; Badoux et al., 2011; Ferrajoli et al., 2008). In addition, it has been studied in combination with rituximab and more recently with ibrutinib (Ferrajoli et al., 2008; Pollyea et al., 2014). Results of lenalidomide given as maintenance therapy are promising (Fink et al., 2017; Foà et al., 2016).

\section{CLL active pathways mediated by the microenvironment WNT signaling}

WNT was first described in a model of breast cancer (Nusse \& Varmus, 1982). Canonical and non- canonical 
WNT signaling are both active in CLL; this is due to the high levels of several molecules produced by the microenvironment including Wnt3, Wnt5b, Wnt6, Wnt10a, Wnt14, and Wnt16 (Lu et al., 2004; Yu et al., 2016). In contrast to mature normal leukocytes, CLL cells express on their surface ROR1, a tyrosine-kinase-like transmembrane receptor whose higher expression level has been associated with a worse patient's outcome (Cui et al., 2016). WNT5a crosslinks ROR1/ROR2 inducing the activation of RAC1 and RHOA and thereby promoting CLL cell proliferation and migration (Fig. 1) (Yu et al., 2016). An antiROR1 monoclonal antibody is currently being investigated in a phase 1 clinical trial (NCT02222688/NCT02860676) as a new treatment for CLL (Choi et al., 2015; Yu et al., 2017). In addition, mutations and methylation alterations in members of this pathway have been observed, together with the finding of a CLL risk locus at the LEF1 gene (Kulis et al., 2012; Wang et al., 2014; Berndt et al., 2013).

\section{NOTCH1 signaling}

Notch signaling is an evolutionary conserved signaling system shared by many multicellular organisms (ArtavanisTsakonas et al., 1999). In humans there are four receptors NOTCH1, NOTCH2, NOTCH3 and NOTCH4 (Andersson et al., 2011). These transmembrane receptors bind to ligands that are other transmembrane proteins; thus, the signaling is induced by cells in proximity (Fig. 1). Receptorligand crosslinking promotes conformational changes, inducing the release of the intracellular portion to the nucleolus and provoking the expression of several genes (Kopan \& Ilagan, 2009). Mutations of NOTCH1 can be observed in $2 \%-14 \%$ of patients with CLL and have been correlated with resistance of anti-CD20 monoclonal antibodies, treatment refractoriness, and disease transformation (Fabbri et al., 2011; Puente et al., 2011; Quesada et al., 2011; Rossi et al., 2012; Wang et al., 2011). The majority of NOTCH1 mutations increase the stability of the intracellular portion (Fabbri \& Dalla-Favera, 2016). In addition, NOTCH1 signaling is active in the leukemic cells in a high proportion of patients (50\%) despite the absence of mutation. This is believed to be due to the expression of the ligands on the CLL cells and the microenvironment, but other ligand-independent mechanisms (e.g. cross activation by other signaling pathways, vesicle trafficking) could also participate (Fabbri et al., 2017; Rosati et al., 2009).

\section{$N F-k B$}

The NF-kB (nuclear factor kappa-light-chain-enhancer of activated $B$ cells) as indicated by its name was first described in B cells (Sen \& Baltimore, 1986). However, NF-kB is present in many cells and controls the expression of genes that influence the immune response, growth, differentiation, survival, development, as well as tumorigenesis and metastasis (Smale, 2011). Two NF-kB main activation pathways have been described: the classical or canonical pathway and alternative or non-canonical pathway (Hayden \& Ghosh, 2008). In CLL, both signaling pathways seem to be activated by microenvironmentrelated molecules such as $\mathrm{CD} 40 \mathrm{~L}$ for the canonical pathway and BAFF or APRIL for both, the canonical and non-canonical pathway (Fig. 1) (Furman et al., 2000; Endo et al., 2007; Ferrer et al., 2014). Mutations affecting these pathways are infrequent in CLL; thus alterations in BIRC3 are observed in $0.4 \%$ of patients at diagnosis and $8.6 \%$ in patients requiring treatment (Baliakas et al., 2015; Chiaretti et al., 2014; Cortese et al., 2014). Mutations in MYD88 can also induce the activation of the NF-kB. MyD88 is an adaptor protein required for signaling from Toll-like receptors and receptors of the interleukin-1 family. In CLL, approximately $3 \%$ of cases present mutations in this gene and most of them represent the gain-of-function L265P mutation that promotes the constitutive activation of the NF-kB (Puente et al., 2011; Landau et al., 2013; Mansouri et al., 2016; Ntoufa et al., 2016). Finally, NF-kB activation by BAFF in CLL cells can induce the activation of BCR signaling by SYK and avoid the BTK and PI3K inhibition (Paiva et al., 2017).

\section{CXCR4/CXCL12 signaling}

The chemokine stromal cell-derived factor-1 (SDF-1)/ CXCL12 is the single ligand for the chemokine receptor CXCR4 (Fig. 1). The interactions between CXCL12 and CXCR4 affect the survival, proliferation, and migration of cells as well as angiogenesis and tumor metastasis. Both molecules are widely expressed by multiple cell types, including several immune cells, stem cells, endothelial cells and stromal cells (Guo et al., 2016; Han et al., 2014). In CLL, CXCR4 is highly expressed on the membrane of the peripheral blood leukemic cells to move into a better environment (Mohle et al., 1999). Chiorazzi's group identified CXCR4 as a key molecule in their model of the life-cycle of CLL cells, where the surface expression of CXCR4 is associated with the location of the leukemic cells; leaving and entering the tissue (Calissano et al., 2011). Treatment strategies targeting both proteins are under investigation. CXCR4 antagonists include T140, AMD3100 (Plerixafor) and MDX-1338/BMS 93656 (Burger \& Peled, 2009). In a phase I clinical trial in relapsed CLL patients, mobilization of CLL cells to the peripheral blood was observed with plerixafor in combination with rituximab (NCT00694590) (Andritsos et al., 2010). NOX-A12 is a Spiegelmer (L-RNA aptamer) that binds and antagonizes CXCL12. In vitro, it inhibits CLL-cell migration and sensitizes to cytotoxic agents (Hoellenriegel et al., 2014). NOX-A12 has been tested in relapsed CLL patients in combination with bendamustine and rituximab in a phase IIa trial (NCT01486797) (Steurer et al., 2014). 


\section{Conclusions}

The pace at which the understanding of the biology of CLL has increased over the last two decades is impressive and it has opened the door to new treatment compounds that target specific disease pathways (i.e. BCRi and BCL2i). These agents are effective in disease settings (e.g. del17p/ TP53mutations) where conventional chemo(immuno)therapy fails. As a result, treatment algorithms for CLL are changing. Hopefully, as other critical molecular pathways and their interactions (e.g. ROR1, NOTCH1 BAFF/APRIL, CXCR4/CXCL12, PD1/PDL1, Mcl-1, SYK, CDK9 and CSF1R) are unraveled, newer and more effective pathway inhibitors will appear and so on hold promise for an even more effective therapeutic armamentarium. The introduction of CLL pathways inhibitors, however, does not convey the end of chemo(immuno) therapy in the management of this form of leukemia, rather their combined use is a most promising strategy in CLL therapy. Pathway inhibitors pose some issues that deserve investigation: best treatment combinations (e.g. BCRi + BCL2i, monoclonal antibodies [and or cytotoxic agents] + pathway inhibitors); optimal dose and schedule (including treatment duration), identification of specific predictive factors, mechanisms of resistance to therapy, and how to overcome them are the most important questions to be addressed.

\section{Acknowledgements \\ Not applicable}

Funding

Not applicable

Availability of data and materials

Not applicable

\section{Authors' contributions}

GF and EM designed the study and wrote the manuscript. Both authors read and approved the final manuscript.

\section{Authors' information}

G.F. obtained his PhD in 2012 at the University of Barcelona and he is currently studying chronic lymphocytic leukemia as a postdoctoral trainee at the Karches Center for Oncology Research, The Feinstein Institute for Medical Research in New York. G.F. is author of more than 20 scientific publications. E.M. is now Professor of Medicine Emeritus at the Institute of Hematology and Oncology, Hospital Clínic, University of Barcelona. His main areas of interest are chronic lymphoproliferative disorders and lymphomas. E.M. is one of the founding members of the International Workshop on Chronic Lymphocytic Leukemia (IWCLL), the European Hematology Association (EHA) of which he has also been President, and the Society of Hematologic Oncology $(\mathrm{SOHO})$. He is board member and past-president of the European Research Initiative on CLL (ERIC). E.M. is author of more than 300 scientific publications, board member and regular reviewer of high impact journals in hematology and oncology.

Ethics approval and consent to participate

Not applicable

\section{Consent for publication}

Not applicable

\section{Competing interests}

The authors declare no competing financial interests.

\section{Publisher's Note}

Springer Nature remains neutral with regard to jurisdictional claims in published maps and institutional affiliations.

\section{Author details}

${ }^{1}$ Karches Center for Oncology Research, The Feinstein Institute for Medical Research, Northwell Health, Manhasset, NY, USA. ²Department of Hematology, Institute of Hematology and Oncology, University of Barcelona, Hospital Clínic, Villarroel 170, 08036 Barcelona, Spain.

Received: 24 January 2018 Accepted: 13 February 2018

Published online: 15 March 2018

\section{References}

Advani RH, Buggy JJ, Sharman JP, Smith SM, Boyd TE, Grant B, et al. Bruton tyrosine kinase inhibitor ibrutinib (PCl-32765) has significant activity in patients with relapsed/refractory B-cell malignancies. J Clin Oncol. 2013;31(1):88-94.

Ahn IE, Underbayev C, Albitar A, Herman SE, Tian X, Maric I, et al. Clonal evolution leading to ibrutinib resistance in chronic lymphocytic leukemia. Blood. 2017;129(11):1469-79.

Andersson ER, Sandberg R, Lendahl U. Notch signaling: simplicity in design, versatility in function. Development. 2011;138(17):3593-612.

Andreotti AH, Schwartzberg PL, Joseph RE, Berg LJ. T-cell signaling regulated by the Tec family kinase, Itk. Cold Spring Harb Perspect Biol. 2010;2(7):a002287.

Andritsos L, Byrd JC, Jones JA, Hewes B, Kipps TJ, Hsu FJ, et al. Preliminary results from a phase I dose escalation study to determine the maximum tolerated dose of Plerixafor in combination with rituximab in patients with relapsed chronic lymphocytic leukemia. Blood. 2010;116(21) ASH annual meeting abstract n.2450

Artavanis-Tsakonas S, Rand MD, Lake RJ. Notch signaling: cell fate control and signal integration in development. Science. 1999;284(5415):770-6.

Atkinson BT, Ellmeier W, Watson SP. Tec regulates platelet activation by GPVI in the absence of Btk. Blood. 2003;102(10):3592-9.

Badoux XC, Keating MJ, Wen S, Lee BN, Sivina M, Reuben J, et al. Lenalidomide as initial therapy of elderly patients with chronic lymphocytic leukemia. Blood. 2011;118(13):3489-98.

Balakrishnan K, Peluso M, Fu M, Rosin NY, Burger JA, Wierda WG, et al. The phosphoinositide-3-kinase (PI3K)-delta and gamma inhibitor, IPI-145 (Duvelisib), overcomes signals from the PI3K/AKT/S6 pathway and promotes apoptosis in CLL. Leukemia. 2015;29(9):1811-22.

Baliakas P, Hadzidimitriou A, Sutton LA, Rossi D, Minga E, Villamor N, et al. Recurrent mutations refine prognosis in chronic lymphocytic leukemia. Leukemia. 2015;29(2):329-36.

Berndt SI, Skibola CF, Joseph V, Camp NJ, Nieters A, Wang Z, et al. Genome-wide association study identifies multiple risk loci for chronic lymphocytic leukemia. Nat Genet. 2013;45(8):868-76.

Bieging KT, Mello SS, Attardi LD. Unravelling mechanisms of p53-mediated tumour suppression. Nat Rev Cancer. 2014;14(5):359-70.

Billard C. Design of novel $\mathrm{BH} 3$ mimetics for the treatment of chronic lymphocytic leukemia. Leukemia. 2012;26(9):2032-8.

Billard C. Apoptosis inducers in chronic lymphocytic leukemia. Oncotarget. 2014; 5(2):309-25.

Bose P, Gandhi V, Konopleva M. Pathways and mechanisms of venetoclax resistance. Leuk Lymphoma. 2017;58(9):1-17.

Brown JR, Byrd JC, Coutre SE, Benson DM, Flinn IW, Wagner-Johnston ND, et al. Idelalisib, an inhibitor of phosphatidylinositol 3-kinase p110delta, for relapsed/ refractory chronic lymphocytic leukemia. Blood. 2014;123(22):3390-7.

Brown JR, Hillmen P, O'Brien S, Barrientos JC, Reddy NM, Coutre SE, et al. Extended follow-up and impact of high-risk prognostic factors from the phase 3 RESONATE study in patients with previously treated CLL/SLL. Leukemia. 2018;32(1):83-91.

Burger JA, Buggy JJ. Bruton tyrosine kinase inhibitor ibrutinib (PCl-32765). Leuk Lymphoma. 2013;54(11):2385-91.

Burger JA, Chiorazzi N. B cell receptor signaling in chronic lymphocytic leukemia. Trends Immunol. 2013;34(12):592-601.

Burger JA, Keating MJ, Wierda WG, Hartmann E, Hoellenriegel J, Rosin NY, et al. Safety and activity of ibrutinib plus rituximab for patients with high-risk chronic lymphocytic leukaemia: a single-arm, phase 2 study. Lancet Oncol. 2014;15(10):1090-9.

Burger JA, Landau DA, Taylor-Weiner A, Bozic I, Zhang H, Sarosiek K, et al. Clonal evolution in patients with chronic lymphocytic leukaemia developing resistance to BTK inhibition. Nat Commun. 2016;7:11589. 
Burger JA, Peled A. CXCR4 antagonists: targeting the microenvironment in leukemia and other cancers. Leukemia. 2009;23(1):43-52.

Byrd JC, Brown JR, O'Brien S, Barrientos JC, Kay NE, Reddy NM, et al. Ibrutinib versus ofatumumab in previously treated chronic lymphoid leukemia. N Engl J Med. 2014;371(3):213-23.

Byrd JC, Furman RR, Coutre SE, Flinn IW, Burger JA, Blum KA, et al. Targeting BTK with ibrutinib in relapsed chronic lymphocytic leukemia. N Engl J Med. 2013; 369(1):32-42

Calissano C, Damle RN, Marsilio S, Yan XJ, Yancopoulos S, Hayes G, et al. Intraclonal complexity in chronic lymphocytic leukemia: fractions enriched in recently born/divided and older/quiescent cells. Mol Med. 2011;17(11-12):1374-82.

Cervantes-Gomez F, Lamothe B, Woyach JA, Wierda WG, Keating MJ, Balakrishnan K, et al. Pharmacological and protein profiling suggests Venetoclax (ABT-199) as optimal partner with Ibrutinib in chronic lymphocytic leukemia. Clin Cancer Res. 2015:21(16):3705-15.

Chanan-Khan AA, Chitta K, Ersing N, Paulus A, Masood A, Sher T, et al. Biological effects and clinical significance of lenalidomide-induced tumour flare reaction in patients with chronic lymphocytic leukaemia: in vivo evidence of immune activation and antitumour response. Br J Haematol. 2011:155(4):457-67.

Cheah CY, Fowler NH. Idelalisib in the management of lymphoma. Blood. 2016; 128(3):331-6

Chen Cl, Bergsagel PL, Paul H, Xu W, Lau A, Dave N, et al. Single-agent lenalidomide in the treatment of previously untreated chronic lymphocytic leukemia. J Clin Oncol. 2011;29(9):1175-81.

Chen SS, Chang BY, Chang S, Tong T, Ham S, Sherry B, et al. BTK inhibition results in impaired CXCR4 chemokine receptor surface expression, signaling and function in chronic lymphocytic leukemia. Leukemia. 2016;30(4):833-43.

Cheng S, Guo A, Lu P, Ma J, Coleman M, Wang YL. Functional characterization of BTK(C481S) mutation that confers ibrutinib resistance: exploration of alternative kinase inhibitors. Leukemia. 2015;29(4):895-900.

Chiaretti S, Marinelli M, Del Giudice I, Bonina S, Piciocchi A, Messina M, et al. NOTCH1, SF3B1, BIRC3 and TP53 mutations in patients with chronic lymphocytic leukemia undergoing first-line treatment: correlation with biological parameters and response to treatment. Leuk Lymphoma. 2014; 55(12):2785-92

Choi MY, Widhopf GF, 2nd, Wu CC, Cui B, Lao F, Sadarangani A, et al. Pre-clinical specificity and safety of UC-961, a first-in-class monoclonal antibody targeting ROR1. Clin Lymphoma Myeloma Leuk. 2015;15 \:S167-S169.

Cimmino A, Calin GA, Fabbri M, lorio MV, Ferracin M, Shimizu M, et al. miR-15 and miR-16 induce apoptosis by targeting BCL2. Proc Natl Acad Sci U S A. 2005;102(39):13944-9.

Cortese D, Sutton LA, Cahill N, Smedby KE, Geisler C, Gunnarsson R, et al. On the way towards a 'CLL prognostic index': focus on TP53, BIRC3, SF3B1, NOTCH1 and MYD88 in a population-based cohort. Leukemia. 2014;28(3):710-3.

Cui B, Ghia EM, Chen L, Rassenti LZ, DeBoever C, Widhopf GF 2nd, et al. Highlevel ROR1 associates with accelerated disease progression in chronic lymphocytic leukemia. Blood. 2016;128(25):2931-40.

Damle RN, Wasil T, Fais F, Ghiotto F, Valetto A, Allen SL, et al. Ig V gene mutation status and CD38 expression as novel prognostic indicators in chronic lymphocytic leukemia. Blood. 1999;94(6):1840-7.

Davis RE, Ngo VN, Lenz G, Tolar P, Young RM, Romesser PB, et al. Chronic active B-cell-receptor signalling in diffuse large B-cell lymphoma. Nature. 2010; 463(7277):88-92.

de Gorter DJ, Beuling EA, Kersseboom R, Middendorp S, van Gils JM, Hendriks RW, et al. Bruton's tyrosine kinase and phospholipase Cgamma2 mediate chemokine-controlled B cell migration and homing. Immunity. 2007;26(1):93-104.

Duhren-von Minden M, Ubelhart R, Schneider D, Wossning T, Bach MP, Buchner $\mathrm{M}$, et al. Chronic lymphocytic leukaemia is driven by antigen-independent cell-autonomous signalling. Nature. 2012;489(7415):309-12.

Endo T, Nishio M, Enzler T, Cottam HB, Fukuda T, James DF, et al. BAFF and APRIL support chronic lymphocytic leukemia B-cell survival through activation of the canonical NF-kappaB pathway. Blood. 2007;109(2):703-10.

Engelman JA, Luo J, Cantley LC. The evolution of phosphatidylinositol 3-kinases as regulators of growth and metabolism. Nat Rev Genet. 2006; 7(8):606-19.

Fabbri G, Dalla-Favera R. The molecular pathogenesis of chronic lymphocytic leukaemia. Nat Rev Cancer. 2016;16(3):145-62.

Fabbri G, Holmes AB, Viganotti M, Scuoppo C, Belver L, Herranz D, et al. Common nonmutational NOTCH1 activation in chronic lymphocytic leukemia. Proc Natl Acad Sci U S A. 2017;114(14):E2911-E9.
Fabbri G, Rasi S, Rossi D, Trifonov V, Khiabanian H, Ma J, et al. Analysis of the chronic lymphocytic leukemia coding genome: role of NOTCH1 mutational activation. J Exp Med. 2011;208(7):1389-401.

Ferrajoli A, Lee BN, Schlette EJ, O'Brien SM, Gao H, Wen S, et al. Lenalidomide induces complete and partial remissions in patients with relapsed and refractory chronic lymphocytic leukemia. Blood. 2008;111(11):5291-7.

Ferrer G, Bosch R, Hodgson K, Tejero R, Roue G, Colomer D, et al. B cell activation through CD40 and IL4R ligation modulates the response of chronic lymphocytic leukaemia cells to BAFF and APRIL. Br J Haematol. 2014;164(4):570-8.

Fink AM, Bahlo J, Robrecht S, Al-Sawaf O, Aldaoud A, Hebart H, et al. Lenalidomide maintenance after first-line therapy for high-risk chronic lymphocytic leukaemia (CLLM1): final results from a randomised, doubleblind, phase 3 study. Lancet Haematol. 2017:4(10):e475-e86.

Foà R, Schuh A, Zaritskey A, Semochkin S, Simpson D, Egyed M, et al. Results of the phase 3 study of Lenalidomide versus placebo as maintenance therapy following second-line treatment for patients with chronic lymphocytic leukemia (the CONTINUUM trial). Blood. 2016;128(22) ASH annual meeting abstract n.230

Forum UC. Ibrutinib for relapsed/refractory chronic lymphocytic leukemia: a UK and Ireland analysis of outcomes in 315 patients. Haematologica. 2016 101(12):1563-72.

Fruman DA, Cantley LC. Idelalisib-a PI3Kdelta inhibitor for B-cell cancers. N Engl J Med. 2014;370(11):1061-2.

Furman RR, Asgary Z, Mascarenhas JO, Liou HC, Schattner EJ. Modulation of NFkappa B activity and apoptosis in chronic lymphocytic leukemia B cells. J Immunol. 2000;164(4):2200-6.

Furman RR, Sharman JP, Coutre SE, Cheson BD, Pagel JM, Hillmen P, et al. Idelalisib and rituximab in relapsed chronic lymphocytic leukemia. N Engl J Med. 2014;370(11):997-1007.

Guo F, Wang Y, Liu J, Mok SC, Xue F, Zhang W. CXCL12/CXCR4: a symbiotic bridge linking cancer cells and their stromal neighbors in oncogenic communication networks. Oncogene. 2016;35(7):816-26.

Hallek M. Chronic lymphocytic leukemia: 2017 update on diagnosis, risk stratification, and treatment. Am J Hematol. 2017;92(9):946-65.

Hamazaki Y, Kojima H, Mano H, Nagata Y, Todokoro K, Abe T, et al. Tec is involved in $\mathrm{G}$ protein-coupled receptor- and integrin-mediated signalings in human blood platelets. Oncogene. 1998;16(21):2773-9.

Hamblin TJ, Davis Z, Gardiner A, Oscier DG, Stevenson FK. Unmutated Ig V(H) genes are associated with a more aggressive form of chronic lymphocytic leukemia. Blood. 1999;94(6):1848-54.

Han TT, Fan L, Li JY, Xu W. Role of chemokines and their receptors in chronic lymphocytic leukemia: function in microenvironment and targeted therapy. Cancer Biol Ther. 2014;15(1):3-9.

Hanahan D, Weinberg RA. Hallmarks of cancer: the next generation. Cell. 2011; 144(5):646-74

Hayden MS, Ghosh S. Shared principles in NF-kappaB signaling. Cell. 2008;132(3):344-62

Hoellenriegel J, Zboralski D, Maasch C, Rosin NY, Wierda WG, Keating MJ, et al. The Spiegelmer NOX-A12, a novel CXCL12 inhibitor, interferes with chronic lymphocytic leukemia cell motility and causes chemosensitization. Blood. 2014;123(7):1032-9.

Honigberg LA, Smith AM, Sirisawad M, Verner E, Loury D, Chang B, et al. The Bruton tyrosine kinase inhibitor PCl-32765 blocks B-cell activation and is efficacious in models of autoimmune disease and B-cell malignancy. Proc Natl Acad Sci U S A. 2010;107(29):13075-80.

Hussain SR, Cheney CM, Johnson AJ, Lin TS, Grever MR, Caligiuri MA, et al. MCl-1 is a relevant therapeutic target in acute and chronic lymphoid malignancies: down-regulation enhances rituximab-mediated apoptosis and complementdependent cytotoxicity. Clin Cancer Res. 2007;13(7):2144-50.

Itchaki G, Brown JR. Lenalidomide in the treatment of chronic lymphocytic leukemia. Expert Opin Investig Drugs. 2017;26(5):633-50.

Jain P, Keating MJ, Wierda WG, Sivina M, Thompson PA, Ferrajoli A, et al. Longterm follow-up of treatment with Ibrutinib and rituximab in patients with high-risk chronic lymphocytic leukemia. Clin Cancer Res. 2017;23(9):2154-8.

Jones JA, Robak T, Brown JR, Awan FT, Badoux X, Coutre S, et al. Efficacy and safety of idelalisib in combination with ofatumumab for previously treated chronic lymphocytic leukaemia: an open-label, randomised phase 3 trial. Lancet Haematol. 2017:4(3):e114-e26.

Kipps TJ, Stevenson FK, Wu Cl, Croce CM, Packham G, Wierda WG, et al. Chronic lymphocytic leukaemia. Nat Rev Dis Primers. 2017;3 Article n.17008

Kopan R, llagan MX. The canonical notch signaling pathway: unfolding the activation mechanism. Cell. 2009;137(2):216-33. 
Kreuzer K-A, Furman RR, Stilgenbauer S, Dubowy RL, Kim Y, Munugalavadla V, et al. Outcome of patients with complex karyotype in a phase 3 randomized study of Idelalisib plus rituximab for relapsed chronic lymphocytic leukemia. Blood. 2016;128 ASH annual meeting abstract n.192

Kulis M, Heath S, Bibikova M, Queiros AC, Navarro A, Clot G, et al. Epigenomic analysis detects widespread gene-body DNA hypomethylation in chronic lymphocytic leukemia. Nat Genet. 2012;44(11):1236-42.

Lampson BL, Kasar SN, Matos TR, Morgan EA, Rassenti L, Davids MS, et al. Idelalisib given front-line for treatment of chronic lymphocytic leukemia causes frequent immune-mediated hepatotoxicity. Blood. 2016;128(2):195-203.

Landau DA, Carter SL, Stojanov P, McKenna A, Stevenson K, Lawrence MS, et al. Evolution and impact of subclonal mutations in chronic lymphocytic leukemia. Cell. 2013;152(4):714-26.

Lannutti BJ, Meadows SA, Herman SE, Kashishian A, Steiner B, Johnson AJ, et al. CAL-101, a p110delta selective phosphatidylinositol-3-kinase inhibitor for the treatment of B-cell malignancies, inhibits PI3K signaling and cellular viability. Blood. 2011;117(2):591-4.

Lazarian G, Guieze R, Wu CJ. Clinical implications of novel genomic discoveries in chronic lymphocytic leukemia. J Clin Oncol. 2017;35(9):984-93.

Li Y, Wang Y, Wang Z, Yi D, Ma S. Racial differences in three major NHL subtypes: descriptive epidemiology. Cancer Epidemiol. 2015;39(1):8-13.

Louie CY, DiMaio MA, Matsukuma KE, Coutre SE, Berry GJ, Longacre TA. Idelalisibassociated enterocolitis: Clinicopathologic features and distinction from other Enterocolitides. Am J Surg Pathol. 2015;39(12):1653-60.

Lu D, Zhao Y, Tawatao R, Cottam HB, Sen M, Leoni LM, et al. Activation of the Wnt signaling pathway in chronic lymphocytic leukemia. Proc Natl Acad Sci U S A. 2004;101(9):3118-23.

Lynch TJ Jr, Kim ES, Eaby B, Garey J, West DP, Lacouture ME. Epidermal growth factor receptor inhibitor-associated cutaneous toxicities: an evolving paradigm in clinical management. Oncologist. 2007;12(5):610-21.

Maddocks KJ, Ruppert AS, Lozanski G, Heerema NA, Zhao W, Abruzzo L, et al. Etiology of Ibrutinib therapy discontinuation and outcomes in patients with chronic lymphocytic leukemia. JAMA Oncol. 2015;1(1):80-7.

Mansouri L, Papakonstantinou N, Ntoufa S, Stamatopoulos K, Rosenquist R. NFkappaB activation in chronic lymphocytic leukemia: a point of convergence of external triggers and intrinsic lesions. Semin Cancer Biol. 2016:39:40-8.

Mato A, Burris HA, Flinn I, Lunning M, Vose J, Fowler N, et al. Long-term followup of the next generation Pi3k-Delta inhibitor Tgr-1202 demonstrates safety and high response rates in CLL: integrated-analysis of Tgr-1202 monotherapy and combined with Ublituximab. Haematologica. 2016;101:50-1.

Mato AR, Lamanna N, Ujjani CS, Brander DM, Hill BT, Howlett C, et al. Toxicities and outcomes of Ibrutinib-treated patients in the United States: large retrospective analysis of 621 real world patients. Blood. 2016;128(22) ASH annual meeting abstract $n .3222$

Minici C, Gounari M, Ubelhart R, Scarfo L, Duhren-von Minden M, Schneider D, et al. Distinct homotypic B-cell receptor interactions shape the outcome of chronic lymphocytic leukaemia. Nat Commun. 2017;8 Article n.15746

Mohle R, Failenschmid C, Bautz F, Kanz L. Overexpression of the chemokine receptor CXCR4 in B cell chronic lymphocytic leukemia is associated with increased functional response to stromal cell-derived factor-1 (SDF-1) Leukemia. 1999;13(12):1954-9.

Ntoufa S, Vilia MG, Stamatopoulos K, Ghia P, Muzio M. Toll-like receptors signaling: a complex network for NF-kappaB activation in B-cell lymphoid malignancies. Semin Cancer Biol. 2016;39:15-25.

Nusse $\mathrm{R}$, Varmus HE. Many tumors induced by the mouse mammary tumor virus contain a provirus integrated in the same region of the host genome. Cell. 1982;31(1):99-109.

O'Brien S, Jones JA, Coutre SE, Mato AR, Hillmen P, Tam C, et al. Ibrutinib for patients with relapsed or refractory chronic lymphocytic leukaemia with $17 p$ deletion (RESONATE-17): a phase 2, open-label, multicentre study. Lancet Oncol. 2016;17(10):1409-18.

O'Brien SM, Furman RR, Coutre SE, Flinn IW, Burger J, Blum K, et al. Five-year experience with single-agent Ibrutinib in patients with previously untreated and relapsed/refractory chronic lymphocytic leukemia/small lymphocytic leukemia. Blood. 2016;128(22) ASH Annual Meeting. Abstract n. 233

Paiva C, Rowland TA, Sreekantham B, Godbersen C, Best SR, Kaur P, et al. SYK inhibition thwarts the BAFF - B-cell receptor crosstalk and thereby antagonizes mcl-1 in chronic lymphocytic leukemia. Haematologica. 2017: 102(11):1890-900

Patel V, Balakrishnan K, Bibikova E, Ayres M, Keating MJ, Wierda WG, et al. Comparison of Acalabrutinib, a selective Bruton tyrosine kinase inhibitor, with Ibrutinib in chronic lymphocytic leukemia cells. Clin Cancer Res. 2017a; 23(14):3734-43.

Patel VM, Balakrishnan K, Douglas M, Tibbitts T, Xu EY, Kutok JL, et al. Duvelisib treatment is associated with altered expression of apoptotic regulators that helps in sensitization of chronic lymphocytic leukemia cells to venetoclax (ABT-199). Leukemia. 2017b;31(9):1872-81.

Philippen A, Diener S, Zenz T, Dohner H, Stilgenbauer S, Mertens D. SYK carries no activating point mutations in patients with chronic lymphocytic leukaemia (CLL). Br J Haematol. 2010;150(5):633-6.

Pollyea DA, Coutre S, Gore L, Adler N, Harris P, Phelps MA, et al. A dose escalation study of Ibrutinib with Lenalidomide for relapsed and refractory chronic lymphocytic leukemia/small lymphocytic lymphoma. Blood. 2014; 124(21) ASH annual meeting abstract n.1987

Pospisilova S, Gonzalez D, Malcikova J, Trbusek M, Rossi D, Kater AP, et al. ERIC recommendations on TP53 mutation analysis in chronic lymphocytic leukemia. Leukemia. 2012;26(7):1458-61.

Puente XS, Pinyol M, Quesada V, Conde L, Ordonez GR, Villamor N, et al. Wholegenome sequencing identifies recurrent mutations in chronic lymphocytic leukaemia. Nature. 2011:475(7354):101-5.

Quesada V, Conde L, Villamor N, Ordonez GR, Jares P, Bassaganyas L, et al. Exome sequencing identifies recurrent mutations of the splicing factor SF3B1 gene in chronic lymphocytic leukemia. Nat Genet. 2011;44(1):47-52.

Roberts AW, Davids MS, Pagel JM, Kahl BS, Puvvada SD, Gerecitano JF, et al. Targeting BCL2 with Venetoclax in relapsed chronic lymphocytic leukemia. N Engl J Med. 2016;374(4):311-22.

Rosati E, Sabatini R, Rampino G, Tabilio A, Di lanni M, Fettucciari K, et al. Constitutively activated notch signaling is involved in survival and apoptosis resistance of B-CLL cells. Blood. 2009:113(4):856-65.

Rossi D, Rasi S, Fabbri G, Spina V, Fangazio M, Forconi F, et al. Mutations of $\mathrm{NOTCH} 1$ are an independent predictor of survival in chronic lymphocytic leukemia. Blood. 2012;119(2):521-9.

Seda V, Mraz M. B-cell receptor signalling and its crosstalk with other pathways in normal and malignant cells. Eur J Haematol. 2015;94(3):193-205.

Sen R, Baltimore D. Multiple nuclear factors interact with the immunoglobulin enhancer sequences. Cell. 1986;46(5):705-16.

Seymour JF, Ma S, Brander DM, Choi MY, Barrientos J, Davids MS, et al. Venetoclax plus rituximab in relapsed or refractory chronic lymphocytic leukaemia: a phase 1b study. Lancet Oncol. 2017;18(2):230-40.

Shehata M, Schnabl S, Demirtas D, Hilgarth M, Hubmann R, Ponath E, et al. Reconstitution of PTEN activity by CK2 inhibitors and interference with the PI3-KVAkt cascade counteract the antiapoptotic effect of human stromal cells in chronic lymphocytic leukemia. Blood. 2010;116(14):2513-21.

Smale ST. Hierarchies of NF-kappaB target-gene regulation. Nat Immunol. 2011; 12(8):689-94.

Smith Cl, Baskin B, Humire-Greiff P, Zhou JN, Olsson PG, Maniar HS, et al. Expression of Bruton's agammaglobulinemia tyrosine kinase gene, BTK, is selectively down-regulated in T lymphocytes and plasma cells. J Immunol. 1994;152(2):557-65.

Souers AJ, Leverson JD, Boghaert ER, Ackler SL, Catron ND, Chen J, et al. ABT-199, a potent and selective $B C L-2$ inhibitor, achieves antitumor activity while sparing platelets. Nat Med. 2013;19(2):202-8.

Stamatopoulos K, Agathangelidis A, Rosenquist R, Ghia P. Antigen receptor stereotypy in chronic lymphocytic leukemia. Leukemia. 2017;31(2):282-91.

Steurer M, Montillo M, Scarfò L, Mauro FR, Andel J, Wildner S, et al. Results from a phase lla study of the anti-CXCL12 Spiegelmer Olaptesed Pegol (NOX-A12) in combination with Bendamustine/rituximab in patients with chronic lymphocytic leukemia. Blood. 2014;124(21) ASH annual meeting abstract $n$. 1996

Stevenson FK, Krysov S, Davies AJ, Steele AJ, Packham G. B-cell receptor signaling in chronic lymphocytic leukemia. Blood. 2011;118(16):4313-20.

Stilgenbauer S, Eichhorst B, Schetelig J, Coutre S, Seymour JF, Munir T, et al. Venetoclax in relapsed or refractory chronic lymphocytic leukaemia with 17p deletion: a multicentre, open-label, phase 2 study. Lancet Oncol. 2016;17(6):768-78.

Strasser A, Cory S, Adams JM. Deciphering the rules of programmed cell death to improve therapy of cancer and other diseases. EMBO J. 2011;30(18):3667-83.

ten Hacken E, Burger JA. Molecular pathways: targeting the microenvironment in chronic lymphocytic leukemia-focus on the B-cell receptor. Clin Cancer Res. 2014;20(3):548-56.

Ten Hacken E, Burger JA. Microenvironment interactions and B-cell receptor signaling in chronic lymphocytic leukemia: implications for disease pathogenesis and treatment. Biochim Biophys Acta. 2016;1863(3):401-13. 
Thompson PA, O'Brien SM, Wierda WG, Ferrajoli A, Stingo F, Smith SC, et al. Complex karyotype is a stronger predictor than del(17p) for an inferior outcome in relapsed or refractory chronic lymphocytic leukemia patients treated with ibrutinib-based regimens. Cancer. 2015;121(20):3612-21.

Tsujimoto Y, Finger LR, Yunis J, Nowell PC, Croce CM. Cloning of the chromosome breakpoint of neoplastic B cells with the $\mathrm{t}(14 ; 18)$ chromosome translocation. Science. 1984;226(4678):1097-9.

Vanhaesebroeck B, Guillermet-Guibert J, Graupera M, Bilanges B. The emerging mechanisms of isoform-specific PI3K signalling. Nat Rev Mol Cell Biol. 2010; 11(5):329-41.

Vetrie D, Vorechovsky I, Sideras P, Holland J, Davies A, Flinter F, et al. The gene involved in X-linked agammaglobulinaemia is a member of the src family of protein-tyrosine kinases. Nature. 1993;361(6409):226-33.

Wang L, Lawrence MS, Wan Y, Stojanov P, Sougnez C, Stevenson K, et al. SF3B1 and other novel cancer genes in chronic lymphocytic leukemia. N Engl J Med. 2011;365(26):2497-506

Wang L, Shalek AK, Lawrence M, Ding R, Gaublomme JT, Pochet N, et al. Somatic mutation as a mechanism of Wnt/beta-catenin pathway activation in CLL. Blood. 2014;124(7):1089-98.

Whitman M, Kaplan DR, Schaffhausen B, Cantley L, Roberts TM. Association of phosphatidylinositol kinase activity with polyoma middle-T competent for transformation. Nature. 1985;315(6016):239-42.

Winqvist M, Asklid A, Andersson PO, Karlsson K, Karlsson C, Lauri B, et al. Realworld results of ibrutinib in patients with relapsed or refractory chronic lymphocytic leukemia: data from 95 consecutive patients treated in a compassionate use program. A study from the Swedish chronic lymphocytic leukemia group. Haematologica. 2016;101(12):1573-80

Woyach JA. How I manage ibrutinib-refractory chronic lymphocytic leukemia. Blood. 2017;129(10):1270-4

Woyach JA, Furman RR, Liu TM, Ozer HG, Zapatka M, Ruppert AS, et al. Resistance mechanisms for the Bruton's tyrosine kinase inhibitor ibrutinib. N Engl J Med. 2014;370(24):2286-94.

Woyach JA, Smucker K, Smith LL, Lozanski A, Zhong Y, Ruppert AS, et al. Prolonged lymphocytosis during ibrutinib therapy is associated with distinct molecular characteristics and does not indicate a suboptimal response to therapy. Blood. 2014;123(12):1810-7.

Wu J, Liu C, Tsui ST, Liu D. Second-generation inhibitors of Bruton tyrosine kinase. J Hematol Oncol. 2016;9(1):80

Yu J, Chen L, Cui B, Widhopf GF 2nd, Shen Z, Wu R, et al. Wnt5a induces ROR1/ ROR2 heterooligomerization to enhance leukemia chemotaxis and proliferation. J Clin Invest. 2016;126(2):585-98.

Yu J, Chen L, Cui B, Wu C, Choi MY, Chen Y, et al. Cirmtuzumab inhibits Wnt5ainduced Rac1 activation in chronic lymphocytic leukemia treated with ibrutinib. Leukemia. 2017:31(6):1333-9.

Zelenetz AD, Barrientos JC, Brown JR, Coiffier B, Delgado J, Egyed M, et al. Idelalisib or placebo in combination with bendamustine and rituximab in patients with relapsed or refractory chronic lymphocytic leukaemia: interim results from a phase 3, randomised, double-blind, placebo-controlled trial. Lancet Oncol. 2017;18(3):297-311.

Zenz T, Habe S, Denzel T, Mohr J, Winkler D, Buhler A, et al. Detailed analysis of p53 pathway defects in fludarabine-refractory chronic lymphocytic leukemia (CLL): dissecting the contribution of 17p deletion, TP53 mutation, p53-p21 dysfunction, and miR34a in a prospective clinical trial. Blood. 2009;114(13): 2589-97.

Zhou Q, Lee GS, Brady J, Datta S, Katan M, Sheikh A, et al. A hypermorphic missense mutation in PLCG2, encoding phospholipase Cgamma2, causes a dominantly inherited autoinflammatory disease with immunodeficiency. Am J Hum Genet. 2012;91(4):713-20

\section{Submit your next manuscript to BioMed Central and we will help you at every step:}

- We accept pre-submission inquiries

- Our selector tool helps you to find the most relevant journal

- We provide round the clock customer support

- Convenient online submission

- Thorough peer review

- Inclusion in PubMed and all major indexing services

- Maximum visibility for your research

Submit your manuscript at www.biomedcentral.com/submit

) Biomed Central 